\title{
The Renaissance of Anonymity
}

\author{
ANDREA RIZZI, University of Melbourne \\ JOHN GRIFFITHS, Monash University
}

IN 1559, POPE Paul IV published a new Index of banned books. In this document, all anonymous works are proscribed. This radical initiative led the print industry to find new strategies to sell its products, including the use of pseudonyms, initials, and other concealing devices. Paul IV's ban was a mighty yet unsuccessful attack on concealed authorship. Anonymity as a deliberate act of concealment on the part of the author, editor, or publisher has continued until the present day. Renaissance scholars encounter the anonymous in different contexts and genres: archival documents (manuscript and print), literature, music, and art. Despite this, scholars seldom question what anonymity is and how it matters to their research. The most common approaches to anonymity are to take Renaissance authorial concealment as an accident (in literature and music) or a default practice (in visual art) before the development of professional artistic figures, copyright laws, and celebrity. An unsigned painting from early fifteenth-century Italy is seen as a norm by Renaissance art historians, as most art works are without signatures and can therefore be categorized as anonymous but awaiting identification. When the modern scholar finally attributes the work as being, for example, from the workshop of Catena or Botticelli, anonymity is discarded, and modern values concerning its aesthetic, cultural, and monetary worth are concomitantly ascribed to it. In most cases where attribution of premodern works is not unequivocal to modern scholars, the works are provisionally classified as anonymous until their authorship is established; but for Renaissance viewers and patrons these works were not anonymous, or at least they were not thought of as such by the intended audience and users. As with secrecy, anonymity demarcates "exclusion, distinction and privilege": intentional

We are most grateful to Elizabeth Horodowich, Stephen Kolsky, Timothy McCall, and Alexander Nagel for their generous comments and suggestions, and we also wish to acknowledge the support of the Australian Research Council. All omissions and blind spots are ours.

${ }^{1} \mathrm{McC}$ all and Roberts, 4. 
anonymity in some cases deliberately restricts or expands access to information and cultural delectation in ways that would not be possible otherwise.

Yet unsigned literary or art works that may be understood as anonymous today may not have been regarded as such by the circles or communities for which they were intended: such communities were infinitely more circumscribed than today. The ubiquitous "Anon." is encountered by literary scholars, musicologists, and historians across multiple genres. Both Michel Foucault and Margreta de Grazia have defined two approaches to anonymity in relation to literature and history. They argue that nonliterary documents have writers, whereas literary texts have authors. The distinction implies that archival documents are authorized by their community whereas literary texts depend on what Foucault dubs "the author function" ${ }^{\prime 2}$ and the notion of ownership. This effectively means that, in the case of the historical document, early modern institutions and communities hold the agency and authorship. The writer is only the conduit or instrument and therefore should not concern the historian. In literature, instead, the author is the validating discourse and the author function should concern the literary scholar. Foucault's and de Grazia's understandings of anonymity in literature and history are not sufficiently nuanced, and create significant distortions. The recent scholarship on English literature discussed here critiques the understanding of the history of anonymity as evolutionary and linear. Instead, there is ample evidence showing that, at least in literature, "anonymity is not simply a residual characteristic of oral or manuscript culture," convention in both print and manuscript cultures.

Recent scholarship on early modern and modern English and Spanish literature provides an innovative and sophisticated understanding of anonymity that applies equally well to all disciplines related to Renaissance studies. This emerging literature explores the nature of intentional anonymity - a form of authorship in which the mask was often a game privy to contemporary readers and viewers. In the words of Marcy North, "anonymity is a flexible convention. It can represent ... an act of modesty or an act of self-protection." "These studies show that anonymity was one of several conventions available to authors, copyists, printers, and patrons for shaping their relationship with the text and reader.

In the present essay we maintain that the conventions of anonymity were practiced in a range of other artistic endeavors (music and the figurative arts) and forms of communication (chronicles, letter-writing, and denunciations, among others) that are yet to receive due attention. Musicologists, historians, and art historians have not yet fully engaged with the Anon. Twenty years ago, former director of the National Gallery and British Museum in London, Neil

\footnotetext{
${ }^{2}$ Foucault.

${ }^{3}$ Griffin, 2003, 15. See also Raven.

${ }^{4}$ North, 14.
} 
MacGregor, asked whether it matters in art history that an artist has a real name. His answer then was "yes," and this concern, which continues in the present day, is a consequence of our conditioning by the legal and cultural notions behind intellectual property, copyright, and the value of a work being increased by knowing the identity of its unique creator. But we are often not privy to the early modern rules of the game and, because of this, are unable to locate anonymity in its material, social, and cultural realms. Foucault and de Grazia have suggested that history and literature deal with texts differently. In the last twenty-five years or so, however, social and cultural historians have turned to literature to understand the Renaissance. Similarly, new literary historicists have devoted much attention to archival material and incorporated it into their analyses of fiction. We believe that this growing interaction between literature, musicology, and history prompts a reconsideration of how anonymity is perceived and studied in these fields.

Recently published studies of literary anonymity, when considered together, challenge scholars of Renaissance literature, history, and music to rethink how they use and interpret the early modern Anon. This new rethinking can assist these scholars in comprehending premodern anonymity. In this essay we aim to broaden the debate around anonymity beyond the confines of English and Spanish literature and to establish a common ground within Renaissance studies. The central question to be addressed is whether the attention of scholars facing early modern anonymity should be placed on the concealed name, and whether their energies are best served by trying to unmask its concealment. In response to this question we agree with Timothy McCall and Sean Roberts that the challenge is "not to ask what in particular early modern Europeans kept secret, but rather to investigate the communicability of these acts." Anonymity is an open secret that does not simply hide a name or label. Rather, it implies a series of conventions that were shared across early modern European communities and textual genres.

The brevity of this essay precludes a fully fledged investigation of the Anon. across Renaissance studies. We aim instead to delineate some of the emerging approaches to anonymity in Renaissance literature, music, and history. Art history has been left out of the picture for two reasons: on the one hand, Renaissance art historians' focus has tended to be directed toward attribution; on the other hand, and following from the first reason, very little has been written about anonymity as an intentional practice.

\section{THE ANONYMITY FUNCTION IN LITERATURE}

Robert Griffin noted in a 2007 article that the general approach taken by scholars working on premodern literature is to see anonymity as an anomaly and an issue that needs to be resolved. His view is that scholarship should stretch the confines 
of what is known and, taking a step further, colonize the unknown, the anonymous, by studying not the alleged author behind it, but the cultural system that underpins it. Following from Griffin, Mark Robson took up the challenge of exploring, through literature, the "ethical stakes of critical response to the anonymous, the unknown, and the strange." By looking at one of the most influential Renaissance thinkers, Robson explains that Erasmus of Rotterdam had no apprehensions about anonymity but he did about wrongly attributed texts. Attribution, argued Erasmus, fossilizes ideas and authorizes errors. Instead, anonymity unleashes the potential of a text and forces the reader to respond critically and ethically to the text. Erasmus's parable of an unidentified man presenting an anonymous Latin text to a distinguished Italian humanist is revealing of the added value he saw in anonymity and the deceit of visible but misattributed authorship. In this story, the scholar is only given the clue that the text is probably by an author of his own time. Upon reading the text, the scholar ridicules its coarseness until the unidentified man tells him that the Latin text was in fact by Cicero, not a contemporary author. This parable shows how false attribution obfuscates the nature and qualities of literature. It follows that the reader and, by extension, the scholar both need to read anonymity ethically by avoiding the tendency to correct, to familiarize, and to restore the text to the closest possible known authorship.

Robson cautions scholars against attributing unassigned and unsigned works at all costs. The anxiety provoked by the unknown and the ensuing urge to attribute a work to an author turns the ascription of a work into a neutralization of the unknown. Robson's approach to anonymity accepts the impossibility, in medieval and early modern literature, of distinguishing between imitation and invention in a text, and between interpretative and appropriative reading. The path to this approach has been paved in recent scholarship by Guillemette Bolens and Lukas Erne on medieval authorship: research on Chaucer, Gower, Shakespeare, Marvell, and Milton points toward the complexities of self-concealing authorship and the need to gain "a fuller account than is currently available." Further, recent studies of accompanying texts or paratexts in the early modern period have broadened our understanding of the strategies adopted by authors, translators, and agents such as editors and printers in both manuscript and print cultures. Marco Paoli's book on dedications provides an important taxonomy of dedicatory and self-fashioning strategies, but unfortunately it leaves out the concealment of authorship enacted by printers to promote their publishing venture. An example of this type of effacement is the 1532 edition by Thomas Berthelette of John Gower's Confessio Amantis where the printer downplays the authority and identity of the author by presenting him as a mere compiler. This example is significant for two reasons: on

${ }^{6}$ Robson, 159.

${ }^{7}$ Bolens and Erne, 18. 
the one hand, it shows that the concealment of authorship did not disappear with the beginning of the Renaissance, and, on the other hand, it demonstrates that there were many points along the chain of production of a text at which concealment of authorship could occur — enacted by the author, translator, patron, copyist, editor, or printer.

The recent scholarship on literary anonymity discussed here turns the dominant perception of anonymity upside-down. The deliberate self-effacement of authorship described by Marcy North and Mark Robson challenges the commonly accepted evolutionary history of authorship: from the anonymous and selfless medieval author to the early modern self-assured and individuated author. The progressive cultural construction of the self did not develop in the Renaissance at the expense of anonymity, and North has disproved such an overstating of the differences between medieval and early modern literature. Her study of anonymity not only provides a fuller account of anonymity as a little-studied expression of authorship, but also calls for a reconsideration of our understanding of authorship itself and, by corollary, the practice of attribution. This reconsideration has been the object of authorship studies for the last forty years or so, spearheaded by Roland Barthes's rejection of the author-centered study of literature. Barthes's approach was further revised and refined by Foucault, who underscored the rejection of the author-centered approach, but remarked that the idea of the author will always be used as a function for the interpretation of texts. As North points out, Foucault's essay does not give proper consideration to anonymity, but still lays the groundwork for its study: the author function is only one of the possible roles contributing to the production of the text; the translator function, patron function, copyist function, editor function, and printer function also play a crucial part in the production and reception of texts. North's investigation of the production, distribution, and reception of manuscript collections of libels shows how the roles of authors, distributors, and readers are often blurred.

Is it possible, therefore, to clearly demarcate the functions of the author, translator, patron, copyist, editor, and printer, especially when one or more of these agents could be effacing the work of the others? The short answer is, in theory, yes, but only if literary scholarship devotes equal attention to the text and the paratext: it is in the interaction between these two that research can extricate the functions and roles played by authorial agents. Work by Donald McKenzie, Helen Smith and Louise Wilson and by Brian Richardson shows that this approach is becoming ever more common, but has only been marginally explored in the study of anonymity. The paratext may not reveal individuated authorship and therefore solve the issue of concealment, but it will reveal the functions played by other authorial agents.

An important example of authorial concealment and the importance of studying paratexts to unveil conventions of anonymity comes from Leon Battista Alberti, a central figure for Jacob Burckhardt's understanding of the Italian 
Renaissance as a period that witnessed the birth of individualism. Contradictorily, in his paratexts Alberti presents conflicting images of himself: confident and ambitious in some of his works, uncertain and defensive in others, Alberti manipulated his authorship by presenting himself in the paratexts with a pseudonym (Lepidus), a new name (Leo), and, in his autobiographical Vita and the Protesta, anonymously. This partial concealment of authorship exposes Alberti's unease with his status as illegitimate son of a destitute Florentine family and a fragile and ambitious literary figure. Martin McLaughlin suggests that by deflecting, veiling, or promoting the authorship of his work, Alberti shifted the weight of authorship from Battista Alberti the man to the patron, to the literary sources used for his writing, to his idealized self, or to the newly coined humanist figure of Leo Baptista Albertus. Whether manuscript or printed, the paratextual material is therefore crucial for understanding how the author, editor, and patron functions play out. It shows how a literary text was intended to be read and interpreted, in the words of de Grazia, as both a work and a document whose author is at the same time the editor, translator, and reader.

\section{THE SOUND OF ANONYMITY}

The study of paratext is yet to evoke sustained interest among musicologists, although it is an area that could add considerable insight to the contextualization of musical sources. Unlike figures such as the lutenist Vincenzo Galilei, whose literary skills are confirmed by a significant output of theoretical writings, books by other instrumentalists such as Antonio de Cabezón or Enríquez de Valderrábano are prefaced by essays of such elegance and erudition that we may suspect them to have been composed by someone other than the the musicians themselves. Such prefaces were customarily left unsigned and there is no suggestion in the works of either Cabezón or Valderrábano that any other writer contributed to their books. It is, however, hard to believe that either of these two musicians had the level of humanistic education necessary to draft such a fine essay in praise of music, or laus musicae. They probably subcontracted a friend, colleague, or professional wordsmith to pen the paratextual essays, and his or her identity has been deliberately withheld. This example elicits important questions about the partial concealment of authorship as a convention underscoring the collaborative nature of music writing. Unfortunately, anonymity has attracted only modest interest among musicologists despite the significant numbers of anonymous works preserved in early sources. It seems that today, more than at the time of their composition, works with confirmed authorial pedigree are preferred over the anonymous. Musicology has thus devoted its energies to trying to unmask the anonymous rather than unmasking the conventions of anonymity. Inquiry into the causes and functions of early modern anonymity is little more than incipient. 
Perhaps the key reason behind this neglect is that musical scholarship has not yet evolved beyond a perception of anonymity principally as the accidental concealment of individuated authorship. In looking at the beginnings of such inquiry, we can point to some specific cases that have started to awaken musicological awareness of deliberate authorial concealment and the conventions of anonymity. One of the best-known cases concerns a presumably unknown composer who used the pseudonym Trebor, and who is the author of six pieces in the early fifteenth-century Chantilly Codex. ${ }^{8}$ While some scholars have suggested that the name may be allied with documented musicians of similar name (Trebol, Triboll, etc.), others have raised the possibility of the deliberate disguise of identity, and that the name is simply Robert spelled backward. Even if a shallow disguise, the fact that this composer has a name at all gives him more credibility in modern terms, especially in comparison to the anonymous works that make up about one-third of the Chantilly manuscript and that are treated with considerably more caution.

The scant interest in exploring anonymity in music history has not been helped by the tradition of author-based collected editions of the works. Even though there are some early exceptions, the practice of editions of corpora is more recent and does ensure greater awareness of works without author attribution. Neither composer-based nor based on a single manuscript, Willi Apel's 1950 edition of French Secular Music of the Late Fourteenth Century brought together a corpus from a number of manuscripts but arranged them in separate volumes of authored and anonymous works. While most of the music that survives from before the fourteenth century is anonymous - with the principal exception of the works of the troubadours and trouvères - after 1300 it is increasingly the norm in music manuscripts for a composer to be identified. This is partly due to the nature of the surviving sources, which in many cases were created as retrospective encyclopedic anthologies compiled after the repertory in question had passed its zenith. Most of the sources of the music of fourteenth-century Italy are of this type, as John Nádas shows. There is a large amount of fifteenth-century liturgical music, however, that survives without indication of authorship. One of the first studies to address this was the edition by Judith Cohen of six anonymous masses based on the L'homme armé theme preserved in Naples. While Cohen's study does not argue for deliberate anonymity, it recognizes the importance of anonymous works in the canon of fifteenth-century music: these works contribute to an understanding of the development of the Mass cycles that many modern historians see as the largescale masterpieces of their time.

More recent recognition of the importance of studying anonymity is found in projects such as "Le Corpus des Messes Anonymes du XVe siècle," directed by Agostino Magro at the Centre d'Études Supérieures de la Renaissance in Tours.

${ }^{8}$ Chantilly, Musée Condé, MS 564 (olim 1047). 
While there is emerging evidence, especially in studies of music printing, that some pieces were published anonymously for various personal or political reasons, or as acts of piracy, there remains scope for further study. In music, much of the difficulty lies in the way that composers are ascribed in both printed and manuscript sources. In this regard, Leeman Perkins in 2009 raised many relevant questions: "How is it possible to untangle conflicting ascriptions and to identify errors of attribution left behind by the scribes and the printers of the time, even where no discrepancies exist? Is it possible to discover how they occurred? Did the mistakes arise from confusion, carelessness, or perhaps even intentional deceit?" 9 These same problems have been probed in more detail in a $2010 \mathrm{PhD}$ dissertation by Zoe Saunders on the corpus of anonymous masses copied in the workshop of renowned Brussels scribe Petrus Alamire. Saunders notes that "musicologists have studied attributed works in the Alamire codices in great detail, but have so far allowed the anonymous works to go virtually unnoticed, [which] is a clear indicator that musicology has been too dependent on the attachment of a known and namable creator to each musical work." While acknowledging that most of the anonymity in these particular manuscripts is probably accidental, she points to the role of intermediaries in the process of creating anonymity, having "established that anonymity was largely a consequence of the knowledge and choices made by the compilers and scribes, to whom authorship was much less meaningful than it is to us today." 11 This last statement may be read as a challenge to contemporary musicology concerning anonymity. On the one hand, scholarship must deal with the implicit illogicality that anonymity supposes inferiority. Anonymous music should not be ignored as if it were cultural residue simply because we do not know the author's name. Moreover, there is a great deal to be learned from weaving together the scant shreds of evidence that unravel the collaboration between composers, patrons, scribes, compilers, and the other agents involved in the production process. Therein lie much deeper understandings of musical artworks and their context.

\section{THE ANONYMOUS IN HISTORY}

Returning once more to the distinction made by Foucault and de Grazia between the literary author and the writer of documents: is there a difference between anonymous historical artifacts and anonymous literary texts? Griffin's collection of sources shows that when faced by texts without names readers still identify an authorial consciousness and "historical, social, and cultural codes that comprise the text." ${ }^{\prime 2}$ He includes a 1780 printed text containing an exchange of

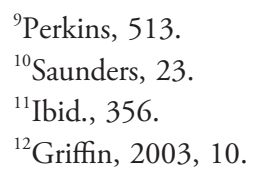


letters between two men. One of them, after almost killing the other, attempted suicide and was eventually hanged for murder. A contemporary reader of this text, Horace Walpole, added a note reading, "I doubt these letters are genuine." ${ }^{\text {"3 }}$ Walpole must have assumed that an author had composed these anonymous letters as a work of fiction. Had Walpole understood the text to be an edited collection of anonymous letters belonging to historical personas he would not have questioned their authenticity in the same way. The reader's decision is based on the perception of genre: in this example Walpole believed this text to be epistolary fiction rather than historical biography. This example shows how readers or scholars make an informed decision on the kind of text they are reading or analyzing. This brings us back to Robson's call for an ethical approach to anonymity, an approach fostered by asking questions around the concealment of authorship in order to avoid an appropriative reading. In the case of the 1780 collection of letters, why are the letters not attributed? Why is the author, editor, or publisher unnamed? Such questions require scholars to search beyond the text and look for paratextual documents that can substantiate the provenance, transmission, and reception of texts.

Lauro Martines's study of social strife and violence in early modern Italy is indicative of the dominant historiographical approach to anonymity. His approach is serial in that he examines, for instance, several anonymous and scathing political rhymes and interprets them as a "memory capsule" giving voice to a history in a way that could be remembered and transmitted easily. ${ }^{14}$ The anonymity of these texts is not examined in any detail as they are seen as documents affirming the oral voices and opinions of a group of their community. These semiliterary texts often did not have a named author because it was dangerous to attack the powerful or the humble. Poets were employed to write and perform verse in order to give voice to praise, censure, wit, and similar expressions. But if some of these poets remained anonymous, others - such as Burchiello - made a reputation for their abrasive and witty verse. Why only some of this poetry is anonymous is not immediately clear; answers to this question would come from examining the reception, dissemination, and presentation of this poetry. Such an investigation would also reveal whether or not some of these poems, which were often copied, rewritten, and bundled into miscellanies, were left anonymous intentionally.

An example of how anonymity discloses more than it hides is a libelous placard described in a court case handled by the Roman tribunal of the governor and recently discussed by Kenneth Stow. On a morning in the year 1620, Ferdinando Ferdini - a Milanese weaver living in Rome - found a nasty anonymous placard affixed onto his house door:

\footnotetext{
${ }^{13}$ Griffin, 2007, 466-67.

${ }^{14}$ Martines, 233.
} 
here lives the embroiderer and big cuckold Ferdinando

and his wife queen of the whores,

Jewish trash

only the executioner would spend time with her.

If you are after the most infamous whores

come here with little money.

Go ahead, sue me, goat

I've got you by the ass

where you normally dip your prick.

You'll have your moustaches cut off. ${ }^{15}$

It is clear that anonymity gave the author of this placard license to utter insult without restraint, made it more difficult for the offended party to act in reprisal, and allowed the author to speak his mind freely — no matter how prejudiced without incurring any loss of reputation from others within his community. At the same time, the concealment of authorship allows the text to be read by its receiver as a collective message: it exposes the practice of mocking the marginalized Jewish community. Anonymity rejects here a clear demarcation between the author, the neighboring community, and the authorizing power of the public opinion, or fama. ${ }^{16}$ More importantly, the authorship of this defamatory message is hidden from us today, as it was for the Roman tribunal, but this does not preclude the local community from knowing the identity of the perpetrators and the motives and context behind such a gesture.

As this example shows, intentional anonymity can reveal more than it conceals: it hides the authorship while at the same time exposing social strife, the voice of public opinion, and gossip. By analyzing this and similar anonymous texts, historians can identify and explain social, economic, and cultural factors that instigated the production of slanderous texts such as the one described here. Ultimately, the identification of authorship is in this case secondary: this libelous text invites the historian to look beyond the text, to search for other similar texts, and to explore the social and cultural contexts that produced it. The placard signifies a complex "system of insult," ${ }^{17}$ social values, and emotions that are enabled by its anonymity. The anonymity of this placard is not a hindrance but an added value.

Anonymity invites the literary scholar, musicologist, and historian to move away from authorship and toward exploration of multiple roles and voices that play crucial functions in the production of a text. By the same token, anonymity alerts scholars to the dangers of anachronism: anonymity does not simply hide

\footnotetext{
${ }^{15}$ The Italian text is in Stow, 71.

${ }^{16}$ On gossip, see Horodowich, 126-33.

${ }^{17}$ Burke, 96 .
} 
a name, but a network of agents whose identity is precluded to the modern reader and scholar, although it was once privately accessible to some members of the community contemporaneous with the text. Expressed in legal terms, unveiling the identity of the perpetrator is not most important; instead, finding the accomplices, the motives behind the act, the codes and practices used to commit the act, and any evidence of how the act was received are key to understanding the text and, ultimately, the collective authorship that makes anonymity possible.

The recognition of anonymity as a cultural and social convention opens up exciting directions for students and scholars of the Renaissance. Certainly the first path is not to eschew the anonymous text but examine it as a vital cultural and social space in which Renaissance intellectuals, artists, copyists, printers, patrons, and the intended audience met "without the mediation of the 'author."'18 Another important direction is to focus on Renaissance translation as a crucial place for the mediation between agents. Often cloaked in anonymity, premodern translation is in most cases the result of collaboration, as Belén Bistué recently demonstrated. There is hardly ever only one name hiding behind a work: studying the anonymous Renaissance is not about naming, but connecting texts, agents, and contexts.

\footnotetext{
${ }^{18}$ Starner and Traister, 8.
} 


\section{BIBLIOGRAPHY}

Apel, Willi. French Secular Music of the Late Fourteenth Century. Cambridge, MA, 1950.

Bistué, Belén. Collaborative Translation and Multi-Version Texts in Early Modern Europe. Farnham, 2013.

Bolens, Guillemette, and Lukas Erne, eds. Medieval and Early Modern Authorship. Tubingen, 2011.

Burke, Peter. The Historical Anthropology of Early Modern Italy: Essays on Perception and Communication. Cambridge, 1987.

Cabezón, Antonio de. Obras de Musica para tecla, arpa y vihuela. Madrid, 1578.

Cohen, Judith, ed. Six Anonymous L'homme Armé Masses in Naples, Biblioteca Nazionale, MS VI E 40. Neuhausen-Stuttgart, 1981.

de Grazia, Margreta. "What Is a Work? What Is a Document?" In New Ways of Looking at Old Texts: Papers of the Renaissance English Text Society, ed. W. Speed Hill, 1:199-207. Binghamton, 1993.

Foucault, Michel. "What Is an Author?" In Modern Criticism and Theory: A Reader, ed. David Lodge and Nigel Wood, 174-87. Harlow, 1999.

Griffin, Robert J., ed. The Faces of Anonymity: Anonymous and Pseudonymous Publication from the Sixteenth to the Twentieth Century. New York, 2003.

- "Working with Anonymity: A Theory of Theory vs. Archive." Literature Compass 4 (2007): 463-69.

Horodowich, Elizabeth. Language and Statecraft in Early Modern Venice. New York, 2008.

MacGregor, Neil. A Victim of Anonymity: The Master of the Saint Bartholomew Altarpiece. New York, 1993.

Martines, Lauro. Strong Words: Writing and Social Strain in the Italian Renaissance. Baltimore, 2003.

McCall, Timothy, and Sean Roberts. "Introduction: Revealing Early Modern Secrecy." In Visual Cultures of Secrecy in Early Modern Europe, ed. Timothy McCall, Sean Roberts, and Giancarlo Fiorenza, 1-23. Kirksville, 2013.

McKenzie, Donald Francis. Bibliography and the Sociology of Texts. Cambridge, 1999.

McLaughlin, Martin. "From Lepidus to Leon Battista Alberti: Naming, Renaming, and Anonymizing the Self in Quattrocento Italy." Romance Studies 31.3-4 (2013): 152-66.

Nádas, John. "The Structure of MS Panciatichi 26 and the Transmission of Trecento Polyphony." Journal of the American Musicological Society 34 (1981): 393-427.

North, Marcy L. The Anonymous Renaissance: Cultures of Discretion in Tudor-Stuart England. Chicago, 2003.

Paoli, Marco. La Dedica: Storia di una strategia editoriale (Italia, Secoli XVI-XIX). Lucca, 2009.

Perkins, Leeman L. "Josquin's Qui habitat and the Psalm Motets." Journal of Musicology 26.4 (2009): 512-65.

Raven, James. "The Anonymous Novel in Britain and Ireland, 1750-1830." In The Faces of Anonymity: Anonymous and Pseudonymous Publication from the Sixteenth to the Twentieth Century, ed. Robert Griffin, 141-66. New York, 2003.

Richardson, Brian. Manuscript Culture in Renaissance Italy. Cambridge, 2009.

Robson, Mark. "The Ethics of Anonymity." In Anonymity in Early Modern England: "What's in a Name?”, ed. Janet Wright Starner and Barbara Howard Traister, 159-75. Farnham, 2011. 
Saunders, Zoe. "Anonymous Masses in the Alamire Manuscripts: Towards a New Understanding of a Repertoire, an Atelier, and a Renaissance Court." PhD diss., University of Maryland, 2010.

Smith, Helen, and Louise Wilson, eds. Renaissance Paratexts. Cambridge, 2011.

Starner, Janet Wright, and Barbara Howard Traister, eds. Anonymity in Early Modern England: "What's in a Name?" Farnham, 2011.

Stow, Kenneth R. "Stigma, Acceptance and the End to Liminality." In At the Margins, Minority Groups in Premodern Italy, ed. Stephen J. Milner, 71-92. Minneapolis, 2005.

Valderrábano, Enriquez de. Libro de Musica de Vibuela, intitulado Silva de sirenas. Valladolid, 1547. 
Copyright of Renaissance Quarterly is the property of University of Chicago Press and its content may not be copied or emailed to multiple sites or posted to a listserv without the copyright holder's express written permission. However, users may print, download, or email articles for individual use. 